\title{
SPORTS INJURIES IN WOMEN: A ONE-YEAR PROSPECTIVE FOLLOW-UP STUDY AT AN OUTPATIENT SPORTS CLINIC
}

\author{
P. KANNUS, MD, S. NIITTYMÄKI, MD and M. JÄRVINEN, MD \\ Tampere Research Station of Sports Medicine and Deptartment of Clinical Sciences, University of Tampere, Finland
}

\section{ABSTRACT}

A one-year prospective follow-up study of all patients visiting Tampere Research Station of Sports Medicine (TRSSM) was carried out in order to determine the specific features of women's sports injuries compared to those of men. During this period 334 women $(31 \%)$ and 745 men $(69 \%)$ visited the station. Women were significantly younger than men and the ten most usual sports events causing the injury differed from those of men. In women acute dislocations, contusions, and fractures were significantly less common in men, while women had more frequent stress-related sports injuries. In both sexes the most common sites of trouble were knee, ankle, and lower back, but in women as opposed to men, the metatarsal area, the toes, and the sole were among the ten most usual sites of the injury. Fourteen women (4\%) and 49 men $(6 \%)$ required operative treatment of the injury. The knee was the most common site of operation in both sexes, in women significantly more frequently than in men.

Key words: Sports, Injuries, Women.

\section{INTRODUCTION}

The community interest in sporting activities has been increased in recent years because of the increased availability of leisure time as well as the belief that general health can be enhanced by improved physical fitness (Ryan, 1978; Devereaux and Lachmann, 1983). With the resultant upsurge in sporting activity there has been an increase in sports injuries, both from acute and from overuse trauma (Fasler, 1976; Devereaux and Lachmann, 1983; Walter et al, 1985).

Numerous epidemiological studies of sports injuries are available (e.g. Robey et al, 1971; Sperryn, 1972; Weightmann and Browne, 1975; Crompton and Tubbs, 1977; Kvist and Järvinen, 1978; Orava, 1980 and 1985; Sandelin et al, 1980 and 1985; Devereaux and Lachmann, 1983; Maehlum and Daljord, 1984). However, surprisingly little has been written about women's sports injuries; their frequency, profile, and specific features (Orava et al, 1981).

The purpose of this prospective investigation was to determine throughout one year follow-up if there were specific features in women's sports injuries compared with men's concerning the injury frequency and location, the patient profile, the sports events and the treatment.

\section{MATERIAL AND METHODS}

The Tampere Research Station of Sports Medicine (TRSSM) is an outpatient sports clinic treating competitive and keepfit athletes mainly from the catchment area of the Tampere University Central Hospital with about $1,000,000$ inhabitants, but top-level athletes from the other parts of the country are also treated. Annually there are approximately 2,000 patient visits at the station.

A one-year prospective follow-up (1 March, 198528 February, 1986) of all women and men visiting the TRSSM was carried out by recording for each visit data on a total of 25 variables. The research form had the coding instructions specified in advance and included all the important patient information: personal data, sports data, date of the visit, reason for the visit, physician in charge of the case, examinations and diagnoses made, treatment provided, and possible subsequent measures.

Address for correspondence:

Pekka Kannus, MD

Tampere Research Station of Sports Medicine

Kaupinpuistonkatu 1

SF-33500 Tampere

Finland
At the end of the collection the data on the research forms were transferred to a DEC 2060 computer at the University of Tampere, and the results were analysed using the BMDP-82 statistical software program (BMDP, 1981). The statistical calculations between the differences of means were done by Student's t-test, of medians by MannWhitney's U-test, and of frequencies by Chi-square test. The given significance levels refer to two-tailed tests.

\section{RESULTS}

During the one-year period 334 women $(31 \%)$ and 745 men $(69 \%)$ visited the TRSSM with a sports injury. The mean and median ages of the women (25.5 and 20 years) were significantly lower than of the men (29.7 and 27 years) ( $p<0.001$ for both). Women (37\%) were more often school pupils than men $(18 \%)(p<0.001)$, while men $(67 \%)$ were more frequently gainfully employed (women $45 \%$ ) $(p<0.001)$. In both sexes the distribution of the patients according to sports activity level was equal: two-thirds of the patients were top-level or competitive, and one-third keep-fit athletes.

The distribution of the patients according to the ten most common sports is presented in Table I. Seven sports events belonged to both women's and men's "top ten". The sports in the women's list that were not in the men's "top ten" were gymnastics ( $9 \%$ of the female patients), dancing $(6 \%)$, and figure skating $(2 \%)$. In the men's list, soccer $(14 \%)$, icehockey $(8 \%) i$, and combined endurance sports (triathlon, etc.) $(4 \%)$ were not in the women's "top ten".

TABLE I

Distribution of injuries according to the ten most common sports.

\begin{tabular}{|c|c|c|c|c|c|}
\hline Women & $\mathbf{N}$ & $\%$ & Men & $\mathbf{N}$ & $\%$ \\
\hline $\begin{array}{l}\text { Gymnastics } \\
\text { Long distance }\end{array}$ & 30 & 9 & $\begin{array}{l}\text { Soccer } \\
\text { Long distance }\end{array}$ & 102 & 14 \\
\hline running & 29 & 9 & running & 78 & 11 \\
\hline Orienteering & 25 & 8 & Orienteering & 64 & 9 \\
\hline $\begin{array}{l}\text { Cross-country } \\
\text { skiing }\end{array}$ & 25 & 8 & $\begin{array}{l}\text { Volleyball } \\
\text { Ice-hockey }\end{array}$ & $\begin{array}{l}61 \\
59\end{array}$ & $\begin{array}{l}8 \\
8\end{array}$ \\
\hline Volleyball & 23 & 7 & Cross-country & & \\
\hline $\begin{array}{l}\text { Dancing } \\
\text { Short distance }\end{array}$ & 19 & 6 & $\begin{array}{l}\text { skiing } \\
\text { Combined endurance }\end{array}$ & 49 & 7 \\
\hline $\begin{array}{l}\text { running } \\
\text { Composite }\end{array}$ & 18 & 6 & $\begin{array}{l}\text { sports } \\
\text { Tennis }\end{array}$ & $\begin{array}{l}31 \\
29\end{array}$ & $\begin{array}{l}4 \\
4\end{array}$ \\
\hline athletic events & 15 & 5 & Composite & & \\
\hline Tennis & 11 & 3 & athletic events & 24 & 3 \\
\hline Figure skating & 8 & 2 & $\begin{array}{l}\text { Short distance } \\
\text { running }\end{array}$ & 19 & 2 \\
\hline
\end{tabular}


Acute dislocations, contusions and fractures were significantly less common in women $(26 \%)$ than in men $(36 \%)$ ( $p<0.001$ ), whereas women had more frequent stress-related muscle compartment syndromes (shin splint, etc.), stress fractures, or nerve entrapment syndromes (women $11 \%$ vs. men $5 \%, p<0.001$ ). Tendinitis, bursitis, or apophysitis were equally common in both sexes.

The ten most common sites of trouble are presented in Table II. In both sexes knee, ankle, and lower back were the three most frequent and equally affected body sites. In women however, the body sites that did not feature in the men's "top ten" were the metatarsal area $(3 \%)$, the toes $(3 \%)$, and the sole $(2 \%)$. In men the shoulder $(7 \%)$, the elbow $(3 \%)$, and the heel $(3 \%)$ did not appear in the women's "top ten".

TABLE \|

The ten most common sites of injury.

\begin{tabular}{lrrlrr}
\hline Women & N & $\%$ & Men & N & $\%$ \\
\hline Knee & 97 & 29 & Knee & 199 & 27 \\
Ankle & 33 & 10 & Ankle & 77 & 10 \\
Lower back & 30 & 9 & Lower back & 65 & 9 \\
Lower leg & 21 & 6 & Shoulder & 55 & 7 \\
Metatarsal region & 11 & 3 & Achilles tendon & 49 & 7 \\
Toes & 10 & 3 & Lower leg & 31 & 4 \\
Calf & 10 & 3 & Hip & 25 & 3 \\
Achilles tendon & 9 & 3 & Elbow & 24 & 3 \\
Sole & 8 & 2 & Heel & 21 & 3 \\
Hip & 6 & 2 & Calf & 21 & 3 \\
& & & & &
\end{tabular}

The modes of treatment provided did not differ between women and men. In both groups "athlete's rest" (referring to restricted activity with respect to sport or activity causing pain or other symptoms), local corticosteroid or glycosamino-glycanpolysulfate (Arteparon ${ }^{(1)}$ injections, and various physical therapies were the most and equally commonly used. Oral drug therapy, orthosis, therapeutic procedure (knee aspiration, etc.), etc. were less common.

Eighty-nine per cent of the women and $91 \%$ of the men did not need any sick leave due to the injury and the length of the leave was usually less than one week in both sexes.

Fourteen women $(4 \%)$ and 49 men $(6 \%)$ needed operative treatment of the sports injury. In both groups the knee joint was the most common site of operation (Table III), in women significantly more frequently $(79 \%)$ than in men $(49 \%)(p<0.05)$.

TABLE III

Site of operation of sports injuries.

\begin{tabular}{|c|c|c|c|c|c|c|}
\hline & Women & $\mathbf{N}$ & $\%$ & Men & $\mathbf{N}$ & $\%$ \\
\hline Knee* & & 11 & 79 & & 24 & 49 \\
\hline Achilles tendon & & - & & & 6 & 12 \\
\hline Ankle & & 1 & 7 & & 5 & 10 \\
\hline Shoulder & & - & & & 4 & 8 \\
\hline Lower leg & & - & & & 2 & 4 \\
\hline Calf & & 1 & 7 & & - & \\
\hline Toes & & 1 & 7 & & - & \\
\hline Other & & - & & & 8 & 17 \\
\hline & & 14 & 100 & & 49 & 100 \\
\hline
\end{tabular}

* $p<0.05$ between women and men

\section{DISCUSSION}

The proportion of females in sports injury surveys has shown an increase during the past decade (Devereaux and Lachmann, 1983; Orava, 1985). Orava (1985) noticed that from 1973 to 1983 overuse injuries in women at outpatients sports clinics had increased from $14.4 \%$ to $18.6 \%$. Devereaux and Lachmann (1983) found in their study at the incidence of female sports injuries rose from $17 \%$ of total in 1981 to $22 \%$ in 1982. In acute sports injuries the proportion of females seems to be between 27\% (Sandelin et al, 1985) and $30 \%$ (Maehlum and Daljord, 1984). In our study of sports injuries the proportion of women was $31 \%$ being almost twice that reported nine years earlier by Kvist and Järvinen (1978) in a very comparable Finnish study at the Outpatient Sports Clinic of Turku.

Two main reasons for the increased female proportion are suggested. Firstly, the increase appears to correspond with an increased female interest in sport and physical activity as noted by Orava et al (1981) and Devereaux and Lachmann (1983). Secondly, females are now much more interested in sports which have not only a high risk of acute injury (football, downhill skiing, judo, karate, etc.) but also of overuse injury (long distance running, cycling, triathlon, indoor ball games, etc.). In these respects women are becoming increasingly similar to men.

In this study women were significantly younger than men. The same observation has been noted in other epidemiological studies (Crompton and Tubbs, 1977; Kvist and Järvinen, 1978; Orava, 1980; Maehlum and Daljord, 1984). Whether this is because the females over 20 years participate less intensely, engage in less injury-prone sports or simply have stopped sport, cannot be determined fully from the present data or the previous studies. Interestingly Orava (1980) has suggested that adolescent girls have a higher stress-injury risk than boys, since before active athletic training the physical activity of girls has generally been lower than that of boys and thus girls' bones and connective tissues might not have been sufficiently adapted to the regular loading of athletic exercises. In his study the training quantities of girls and boys were almost equal.

According to the present study women's most common sports events in respect of injuries have some differences compared with men's (Table I). Women's "top ten" included gymnastics, dancing, and figure skating, which have not been classified as very high risk events. Conversely, in men's "top ten" the events that did not belong to women's list (soccer, ice-hockey, and combined endurance sports) are typical high risk athletic events concerning injury risk (Sandelin et al, 1980). This difference with women having less high risk events may partly explain the noticed lower frequency of acute dislocations, contusions, or fractures in women, and women's higher proportion of some overuse injuries of the lower extremity.

For the overuse injuries women may have a higher risk due to the different body anatomy and biomechanics between women and men (Kujala, 1987). Women have wider hips, lighter bones and less muscle mass to support their more mobile joints, which may dispose to overuse disorders of the lower extremities (Otis, 1986; Kujala, 1987). In the present study the ten most commonly affected body sites of the women were with the exception of lower back the lower extremities and the same kind of observations have been made previously (Kvist and Järvinen, 1978; Orava, 1980 and 1985; Sandelin et al, 1980 and 1985; Devereaux and Lachmann, 1983; Maehlum and Daljord, 1984). 
Both acute and overuse sports injuries are generally considered to be of a relatively mild character (Kvist and Järvinen, 1978; Orava, 1980; Sandelin et al, 1980 and 1985), and this is also evident in this study. The great majority of women and men did not need any sick leave because of their injury and most of the injuries were treated conservatively. However some of the patients $14 \%$ of the women and $6 \%$ of the men) needed operative treatment. In other studies the percentages have been almost the same varying from $4.7 \%$ to $6.9 \%$ (Kvist and Järvinen, 1978; Orava, 1980; Sandelin et al, 1980 and 1985; Maehlum and Daljord, 1984). In women the knee joint was more frequently the site of operation than in men, but the operative indications were similar in both sexes. In women the other operations were also done on the lower limb, which supports the concept of women's high risk of sports injuries to the lower extremities (Otis, 1986).

In conclusion, women's sports injuries seem to have some specific features when compared with men's: their frequency is increasing, they involve younger athletes, they occur partly in different sports events, they are more frequently stress-related than acute and they affect the lower extremities more commonly than other sites.

\section{References}

BMDP Statistical Software, 1981 Dixon, W. J. Ed. Berkeley: Univ. of California Press.
Crompton, B. and Tubbs, N., 1977 "A survey of sports injuries in Birmingham". Brit.J.Sports Med. 11: 12-15.

Devereaux, M. D. and Lachmann, S. M., 1983 "Athletes attending a sports injury clinic - a review". Brit.J.Sports Med. 17: 137-142.

Fasler, S., 1976 "Sportunfälle: Statistik 1963-1973". Soz.Präventivmed. 21 296-301.

Kujala, U., 1987 "Knee exertion injuries in adolescents and young adults". Academic Dissertation, Turku, Finland.

Kvist, M. and Järvinen, M., 1978 "Typical injuries at an outpatient sports clinic". Duodecim. 94: 1335-1345.

Maehlum, S. and Daljord, O. A., 1984 "Acute sports injuries in Oslo: A oneyear study". Brit.J.Sports Med. 18: 181-185.

Orava, S., 1980 "Exertion injuries due to sports and physical exercise". Academic Dissertation, Kokkola, Finland.

Orava, S., Hulkko, A. and Jormakka, E., 1981 "Exertion injuries in female athletes". Brit.J.Sports Med. 15: 229-233.

Orava, S., 1985 "Changes in athletic overuse injuries during ten years". Finn.Sports Exerc.Med. 4: 52-56.

Otis, C. L., 1986 "The female athlete - special concerns". Sports Med.Dig. 8 1-3.

Robey, J. M., Blyth, C. S. and Mueller, F. O., 1971 "Athletic injuries application of epidemiologic methods". JAMA 217: 184-189.

Ryan, A. J., 1978 "Sports medicine today". Science 200: 919-924.

Sandelin, J., Santavirta, S., Kiviluoto, O. and Honkanen, R., 1980 "Sports injuries treated in a casualty ward". Scand.J.Sports Sci. 2: 17-20.

Sandelin, J., Kiviluoto, O., Santavirta, S. and Honkanen, R., 1985 "Outcome of sports injuries treated in a casualty department". Brit.J.Sports Med. 19: 103-106.

Sperryn, P. N., 1972 “Athletic injuries”. Rheum.Phys.Med. 11: 246-249.

Walter, S., Sutton, J., Mclntosh, J. and Conolly, C., 1985 "The aetiology of sports injuries. A review of methodologies". Sports Med. 2: 47-58.

Weightman, D. and Browne, R. C., 1975 "Injuries in eleven selected sports" Brit.J.Sports med. 9: 136-141. 